\title{
Lift the quilt in case of atrial fibrillation and disc prolapse
}

\author{
This article was published in the following Dove Press journal: \\ Vascular Health and Risk Management \\ 21 June 2012 \\ Number of times this article has been viewed
}

\author{
Adam Bastovansky' \\ Kathrin Ziegler ${ }^{2}$ \\ Claudia Stöllberger ${ }^{2}$ \\ Josef Finsterer ${ }^{3}$ \\ 'Department of Radiology, \\ ${ }^{2}$ Medical Department, Krankenanstalt \\ Rudolfstiftung, Vienna, Austria; \\ ${ }^{3}$ Danube University Krems, Krems, \\ Austria
}

Background: Peripheral embolism to the lower extremities may mimic disc prolapse with severe consequences.

Case report: A 71-year-old male with a history of chronic alcoholism developed low back pain radiating to both lower extremities in a nonradicular distribution and bilateral dysesthesias of the distal lower legs after lifting a heavy weight. Given that magnetic resonance imaging (MRI) of the lumbar spine showed disc herniation in L3/4 and L4/5, he was scheduled for laminectomy but was unable to undergo surgery due to thrombocytopenia. After transfer to another hospital, persistence of symptoms and signs, absent pulses on the distal lower legs, and rhabdomyolysis with temporary renal insufficiency, peripheral embolism with compartment syndrome was suspected. Magnetic resonance angiography revealed occlusion of the right superficial femoral artery and long high-grade stenosis of the left superficial and profound femoral arteries and distal arteries. He successfully underwent embolectomy and fasciotomy.

Conclusions: If lumbar pain is not radicular, peripheral pulses are minimally palpable, and distal limbs are cold and show livid decolorization, peripheral embolism is much more likely than disc herniation, particularly if the patient's history is positive for atrial fibrillation. MRI of the lumbar spine must be interpreted in conjunction with clinical presentation.

Keywords: embolism, compartment syndrome, neurosurgery, embolectomy, fasciotomy, rhabdomyolysis

\section{Introduction}

A frequent complication of atrial fibrillation (AF) is stroke or peripheral embolism. ${ }^{1}$ Thrombi from the heart may embolize to the cerebral vessels, inner organ vasculature, or limb arteries. ${ }^{2}$ Embolization in AF may occur subclinically or present with mild, marked, or severe clinical manifestations. ${ }^{3}$ Peripheral embolism may be overlooked when presenting with clinical manifestations of other problems. Here, we report a case of peripheral embolism misdiagnosed as disc herniation.

\section{Case report}

The patient is a 71-year-old Caucasian nonsmoking male with a height of $182 \mathrm{~cm}$ and weight of $80 \mathrm{~kg}$. He was admitted to the hospital for scheduled laminectomy after sudden onset low back pain (visual analog scale [VAS] 10) immediately after lifting wood. He experienced pseudoradicular radiation of pain bilaterally to all toes and weakness in both lower limbs, which caused him to collapse. Consecutive disc prolapses in L3/4 and L4/5 were detected on lumbar magnetic resonance imaging (MRI) (Figure 1). Given that permission to undergo surgery was not granted by
Correspondence: Josef Finsterer Postfach 20, 1180 Vienna, Austria Tel +43 I7| I659 2085

Fax +43 |478 I7II

Email fifigs I@yahoo.de 


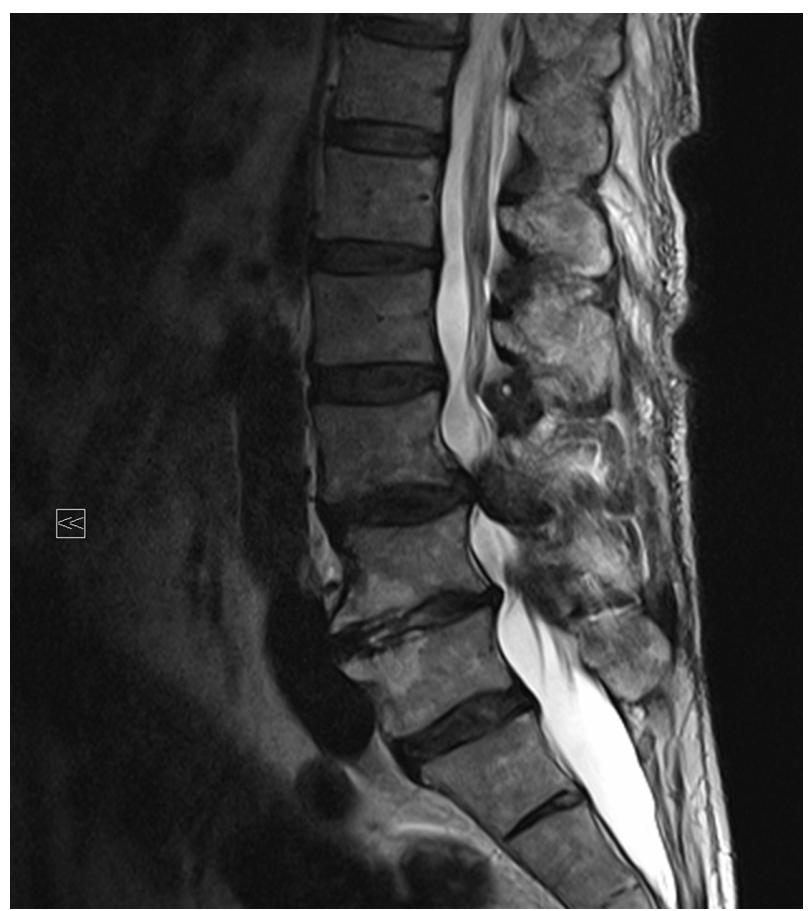

Figure I Magnetic resonance imaging of the lumbar spine showing disc prolapse at L3/L4 with consecutive stenosis of the lumbar canal.

internal medicine physicians because his thrombocytopenia was $35 / \mathrm{nL}$, he requested transfer to our hospital. He had a previous history of chronic alcoholism between the ages of 35 and 45 years (four bottles of beer per day) accompanied by secondary complications such as liver cirrhosis since age 25 , steatosis hepatitis, portal hypertension, esophageal varices grade III - which had been ligated at approximately 17 years of age and a second time 19 months prior to his current hospital admission - calcifying pancreatitis, chronic gastritis since age 14, splenomegaly with consecutive thrombocytopenia since age 8 , pulmonary hypertension, and right ventricular hypertrophy due to hepatopulmonary syndrome since age 1. Previous nonalcohol-related disorders included arterial hypertension, nephrolithiasis during the 1990s, cholecystectomy 8 years previous, AF for the past 5 years, and a gastric polyp, which had been successfully resected 21 months prior to the current hospital admission. Oral anticoagulation had been considered previously but had not been administered.

The patient was admitted to the hospital 1 day after symptom onset. Upon admission, he complained of weakness in the distal left lower limb and paresthesias of both distal lower legs with left-sided predominance. Clinical exam revealed prominent cutaneous veins, weakness of the left distal lower limb (M1), cold distal lower legs with left-sided predominance, and reduced arterial pulses bilaterally with left-sided predominance. The Lasegue sign (straight-leg-raising test) was negative bilaterally. Creatine kinase (CK) was $140 \mathrm{U} / \mathrm{L}$ at the onset of pain, nonmeasurable upon admission in our hospital due to hemolysis, and 15,997 U/L one day after admission (Table 1). Neurosurgeons observed left-sided weakness for foot extension and flexion, pain upon flexion of the left hip and extension of the left knee, livid discoloration and cold left forefoot, and reduced arterial pulses bilaterally. Thus, peripheral artery disease and compartment syndrome were suspected. MR-angiography revealed occlusion of the right superficial femoral artery above the knee and high-grade stenosis of the left superficial and profound femoral arteries and arteries of the left lower leg (Figure 2). On the same day, the patient underwent embolectomy of the right profound femoral artery and left common iliac artery and fasciotomy of the medial left upper and lateral left lower leg. Following surgery, the patient required temporary hemofiltration due to renal insufficiency with oliguria from rhabdomyolysis. After an initial increase, $\mathrm{CK}$ values have been steadily declining (Table 1).

\section{Discussion}

This patient is interesting for several reasons. First, suddenonset lumbar pain was attributed to herniation of lumbar discs L3/4 and L4/5. Although a causal relationship between heavy lifting followed by onset of lumbar pain is suggestive of disc herniation, other pathomechanisms should be considered. A causal relationship between weight lifting and pain onset was unlikely due to bilateral occurrence of pain and an absent radiation of pain in a radicular distribution.

Table I Results of blood tests following embolism

\begin{tabular}{|c|c|c|c|c|c|c|c|c|c|c|c|c|c|}
\hline Parameter & NR & 27.1 & 28.1 & 29.1 & 29.1 & 29.1 & 30.1 & 30.1 & 31.1 & 31.1 & 1.2. & 1.2 & 10.2 \\
\hline Glucose & $60-100 \mathrm{mg} / \mathrm{dL}$ & 169 & 126 & na & na & na & 124 & 144 & 156 & 112 & na & 119 & na \\
\hline Creatinine & $-1.10 \mathrm{mg} / \mathrm{dL}$ & I.I & 1.12 & 1.23 & 1.8 & 1.8 & 1.6 & 1.8 & 1.8 & 1.9 & 1.5 & 2.04 & 1.38 \\
\hline GFR & $<90 \mathrm{~mL} / \mathrm{min} / \mathrm{l} .73 \mathrm{~m}^{2}$ & na & 68 & 61 & na & na & na & na & na & na & na & 34 & 52 \\
\hline CK & $<\mathrm{I} 70 \mathrm{U} / \mathrm{L}$ & 140 & hl & 15,997 & 24,581 & 26,434 & 21,545 & 19,053 & 9246 & 5158 & 3455 & 4229 & 181 \\
\hline Erythrocytes & $4.20-5.50 / \mathrm{pL}$ & na & 4.07 & 4.36 & 3.79 & na & 3.45 & 3.24 & 3.06 & 2.63 & 2.57 & 2.55 & 2.95 \\
\hline Thrombocytes & $150-450 / \mathrm{nL}$ & na & 41 & 40 & 40 & na & 58 & 64 & 56 & 48 & 41 & 48 & 82 \\
\hline
\end{tabular}

Abbreviations: NR, normal range; GFR, glomerular filtration rate; CK, creatine kinase; na, not available; hl, hemolytic. 


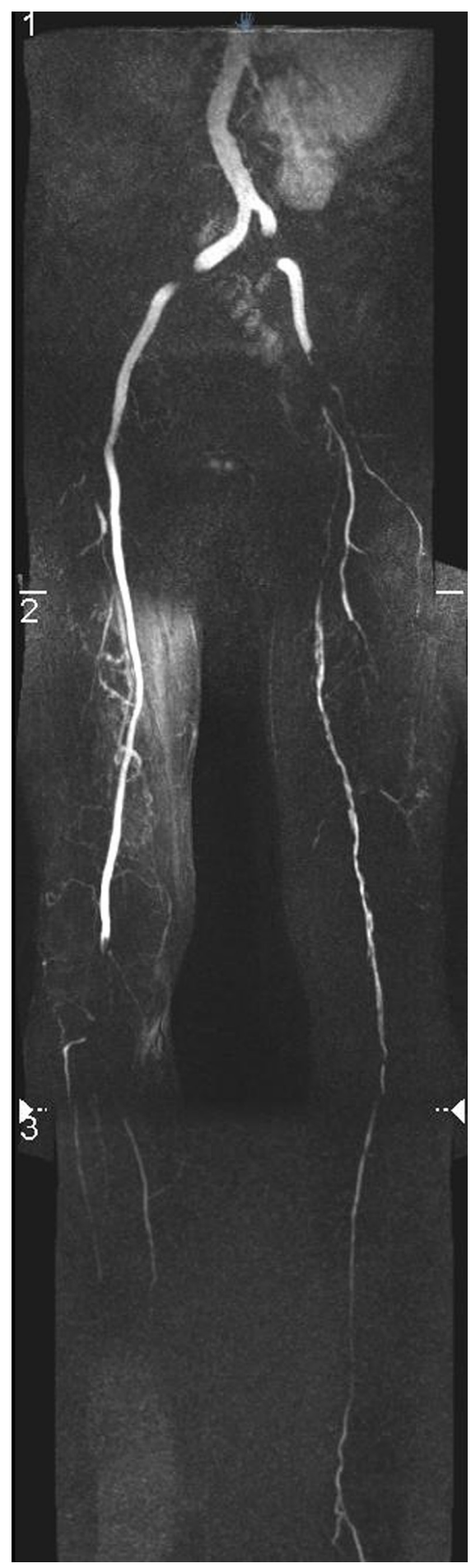

Figure 2 Magnetic resonance angiography showing occlusion of the right superficial femoral artery above the knee and long high-grade stenosis of the left superficial and profound femoral arteries and of the arteries of the left lower leg (arrows).

Further evidence against the causal relationship included reduced or absent arterial pulses on the distal lower limbs bilaterally. Radiation to all toes suggested involvement of radices $\mathrm{L} 5$ and $\mathrm{S} 1$ but not of radices $\mathrm{L} 3$ and $\mathrm{L} 4$ as predicted based on MRI. The bilateral distribution of pain was more suggestive of vertebral stenosis, epidural varices, bilateral psoas abscess, pneumoretroperitoneum, or a proximal vascular problem rather than disc herniation. ${ }^{4-6}$ Unfortunately, the patient was not examined by a neurologist at symptom onset. Thus, the degree of weakness, influence of pain on muscle force, elicitability of tendon reflexes, radiation of pain, and quality and distribution of tentative sensory disturbances were not determined.

Second, a spinal MRI showed disc prolapses in L3/4 and L4/5; however, in a number of cases, imaging findings are over-interpreted or unrelated to clinical presentation. ${ }^{7}$ Particularly for cases in which weakness and wasting are associated with pain or sensory disturbances, a "mechanical" cause is often suggested to explain the clinical presentation. ${ }^{8}$ A "mechanical" explanation is more acceptable than a neural, muscular, or vascular problem. Over-interpretation of spinal MRI results are thus not infrequent and interobserver variability is high, which is explained by inherent weaknesses of the applied method. ${ }^{9,10}$ Imaging methods are thought to be superior to nonimaging methods for diagnosis. However, this may incorrectly lead to interpreting stenosis, compression, or congestion as causative factors. ${ }^{11}$ Thus, analysis of clinical presentation must be thorough. When all aspects of clinical presentation agree with imaging findings, a causative relationship should be considered. Electrophysiological investigation may be useful for differentiating between proximal nerve compression and peripheral artery disease. Furthermore, communication between neurologists, neurosurgeons, and radiologists must improve, and radiologists should be aware of details regarding the clinical presentation and abnormalities observed during clinical exam and nonimaging instrumental investigation.

Third, the diagnosis of disc prolapse was accepted without question by the department, although the patient was transferred without a detailed initial clinical exam or critical review of MRI findings. The patient was reinvestigated and a marked elevation in CK was observed, leading to suspicion of peripheral embolism on the morning of the third day after onset. Indication for resection of disc herniation must be critically reviewed if the diagnosis is provided by another hospital, particularly if pain radiation is not radicular, bilateral, and does not agree with imaging findings. For leg pain, peripheral pulses must always be examined and vascular problems considered, particularly if the Lasegue sign - a strong indicator of herniation - is negative and hip mobility is unaffected. ${ }^{12,13}$ Disc resection should be indicated only if clinical findings can be unambiguously attributed to a mechanical problem of the spine. In cases of uncertainty 
regarding the etiology of symptoms and signs in a given case, all differentials of lumbar and leg pain must be considered and excluded or confirmed.

This case demonstrates that weakness, sensory disturbances, and pain in one limb may not only be attributed to a mechanical spinal problem but also to a vascular pathology. If lumbar pain does not radiate in a radicular distribution, peripheral pulses are absent or only minimally palpable, and distal limbs feel cold and show livid decolorization, peripheral embolism is much more likely than disc herniation, particularly if the patient has a history positive for AF.

\section{Disclosure}

The authors report no conflicts of interest.

\section{References}

1. Healey JS, Connolly SJ, Gold MR, et al. ASSERT Investigators. Subclinical atrial fibrillation and the risk of stroke. $N$ Engl $J$ Med. 2012;366:120-129.

2. Brenyo AJ, Aktas MK. Non-pharmacologic management of atrial fibrillation. Am J Cardiol. 2011;108:317-325.

3. Menke J, Lüthje L, Kastrup A, Larsen J. Thromboembolism in atrial fibrillation. Am J Cardiol. 2010;105:502-510.

4. Ho YP, Su MY, Tsai WS, Tseng JH, Chiu CT, Chen PC. Spontaneously significant pneumoretroperitoneum misinterpreted as herniated intervertebral disc: an unusual presentation of perforation of ascending colon cancer. Dig Dis Sci. 2004;49:1499-1503.
5. Matejovský Ml Z, Matejovská J, Havlík J, Zídková H, Serclová Z, Reisingerová M. Primary retrofascial abscess in the iliopsoas muscle caused by salmonella enteritidis. Acta Chir Orthop Traumatol Cech. 2000;67:138-142.

6. Pennekamp PH, Gemünd M, Kraft CN, von Engelhardt LV, Lüring C, Schmitz A. Epidural varicosis as a rare cause of acute radiculopathy with complete foot paresis - case report and literature review. Z Orthop Ihre Grenzgeb. 2007;145:55-60.

7. Song KJ, Choi BW, Kim GH, Kim JR. Clinical usefulness of CT-myelogram comparing with the MRI in degenerative cervical spinal disorders: is CTM still useful for primary diagnostic tool? J Spinal Disord Tech. 2009;22:353-357.

8. Wassenaar M, van Rijn RM, van Tulder MW, et al. Magnetic resonance imaging for diagnosing lumbar spinal pathology in adult patients with low back pain or sciatica: a diagnostic systematic review. Eur Spine J. 2012;21:220-227.

9. Lurie JD, Tosteson AN, Tosteson TD, et al. Reliability of magnetic resonance imaging readings for lumbar disc herniation in the Spine Patient Outcomes Research Trial (SPORT). Spine (Phila Pa 1976). 2008;33:991-998.

10. Kuijper B, Beelen A, van der Kallen BF, et al. Interobserver agreement on MRI evaluation of patients with cervical radiculopathy. Clin Radiol. 2011;66:25-29.

11. Maus T. Imaging the back pain patient. Phys Med Rehabil Clin N Am. 2010;21:725-766.

12. Capra F, Vanti C, Donati R, Tombetti S, O'Reilly C, Pillastrini P. Validity of the straight-leg raise test for patients with sciatic pain with or without lumbar pain using magnetic resonance imaging results as a reference standard. J Manipulative Physiol Ther. 2011;34:231-238.

13. Łebkowski WJ. Presence and intensity of the Lasegue sign in relation to the site of lumbar intervertebral disc herniation. Chir Narzadow Ruchu Ortop Pol. 2002;67:265-268.
Vascular Health and Risk Management

\section{Publish your work in this journal}

Vascular Health and Risk Management is an international, peerreviewed journal of therapeutics and risk management, focusing on concise rapid reporting of clinical studies on the processes involved in the maintenance of vascular health; the monitoring, prevention and treatment of vascular disease and its sequelae; and the involvement of

\section{Dovepress}

metabolic disorders, particularly diabetes. This journal is indexed on PubMed Central and MedLine. The manuscript management system is completely online and includes a very quick and fair peer-review system, which is all easy to use. Visit http://www.dovepress.com/ testimonials.php to read real quotes from published authors. 